\title{
1D-NMR and 2D-NMR analysis of the thermal degradation products from vitrinites in relation to their natural hydrogen enrichment
}

\author{
M.J. Iglesias ${ }^{a}$, M.J. Cuesta ${ }^{b}$, F. Laggoun-Défarge ${ }^{c}$ and I. Suárez-Ruiz ${ }^{b}$, \\ aÁrea de Química Orgánica, Universidad de Almería, Carretera de Sacramento, 04120 \\ Almería, Spain \\ ${ }^{b}$ Instituto Nacional del Carbón (CSIC), Ap. Co. 73, 33080 Oviedo, Spain \\ ' ISTO/UMR 6113 CNRS-Université d'Orléans, Batiment Géosciences, BP 6759, 45067, \\ Cedex 2, France
}

\section{Abstract}

A study of coal products obtained from Gray-King pyrolysis at $550{ }^{\circ} \mathrm{C}$ was carried out in order to obtain information about the chemical modifications of the huminite/vitrinite structure resulting from different processes of natural hydrogen-enrichment. The high oil yield obtained, the similarity between the infrared spectra of the generated oils and those of the parent vitrinite as well as the parallelism between the compositional data deduced for these oils and those obtained by means of Curie point pyrolysis-gas chromatography/mass spectrometry justify the use of this thermal approach. Gray-King pyrolysis is preferable to other techniques because it is possible to make an accurate mass balance, a thorough study of the solid residues and a full characterization of both the volatile and non-volatile fractions of the degradation products. From a study of selected perhydrous coals, mainly composed of the vitrinite maceral group, only in the low reflectance Jurassic coal from the Whitby (England) basin (WJVl) was the incorporation of lipoidal material evident, due to the significant contribution of long-chain alkyl aromatics in its oil. The structure of the vitrinite in the other Jurassic coals, the high reflectance sample from the Whitby basin (WJVh) and the coals from the Asturias (Spain) and Portugal basins (AJV and PGJV, respectively), is probably similar to that described for non-perhydrous vitrinites in the subbituminous coal rank. However, the presence of assimilated hydrogenated substances of a secondary nature, in particular for AJV and PGJV, hinders the cross-linking and condensation processes typical of the transit to the bituminous coal rank. In Cretaceous coals, from Teruel (Spain) and Utah (EEUU), (TCV and $\mathrm{UCV}$, respectively), whose perhydrous character is mainly due to the specific hydrogenated nature of their botanical precursors, the incorporation of aliphatic structures via covalent oxygen linkages is proposed. The results obtained may be useful for establishing accurate structural models for perhydrous vitrinites. At the same time, the data obtained will contribute to explain the involvement of the high hydrogen content in the suppression of vitrinite reflectance.

Keywords: Perhydrous coal; Perhydrous vitrinites; Pyrolysis; Gray-King; FTIR; GC/MS; NMR 


\section{Introduction}

Natural hydrogen enrichment gives rise to modifications in the macromolecular structure of vitrinite, thus affecting the properties and behaviour of coals. Precise information about such modifications is difficult to obtain mainly due to the analytical inaccessibility of the material. The most suitable approach for studying the chemical structure of coals involves the direct solid-state characterization of their macromolecular network in combination with an analysis of the liquid, and/or gaseous, fractions derived from coals with minimal alteration. Pyrolysis and more specifically, fast micro-scale flash pyrolysis is the most commonly used degradation method in the study of macromolecular materials due to the fact that by employing this technique it is possible to attain small fragments readily available for analysis. It is assumed that this technique mainly yields products of primary degradation. The degradation products are analysed "on line" by means of gas chromatography or gas chromatography/mass spectrometry.

This strategy was used in order to obtain a better understanding of the modifications in the macromolecular structure of six perhydrous coals with respect to those with a normal hydrogen content [1]. These coals, mainly composed of the vitrinite maceral group, are grouped as Cretaceous coals: UCV and TCV (Turonian and Albian age, respectively) and Jurassic coals: AJV, PGJV and WJVh and WJVl (Kimmeridgian and Toarcian, respectively). All of them show a high $\mathrm{H} / \mathrm{C}$ atomic ratio (0.83-1.07), volatile matter (52-72\%) and carbon content $(77-85 \%)$, and an abnormally low reflectance. Vitrinite reflectance is reduced by about $0.2-0.3 \%$ in the Cretaceous coals and by $0.3-0.4 \%$ in the Jurassic ones. In fact, their true rank cannot be determined because their conventional rank parameters have been greatly modified due to high $\mathrm{H}$ concentration. However, it was possible to estimate the coal rank with a certain degree of accuracy as subbituminous and subbituminous/high volatile bituminous coal rank for the Cretaceous and Jurassic samples, respectively [1], [2], [3], [4] and [5]. Although a set of general common features was found for the perhydrous coals, clear chemical-structural differences between the huminite/vitrinites were also detected. Such differences mainly arise from the source of the hydrogen content and the effect that it has on subsequent evolution (natural coalification).

The abnormal hydrogen enrichment in the Cretaceous coals (UCV and TCV) is of a presedimentary type (before peatification) as a result of the extremely lipid-rich nature of their botanical precursors. This lipid-rich nature was caused by the saturation of the botanical tissues, generally composed of lignin and cellulose, by terpene-type resin [1], [2] and [6]. The differences between these two coals are attributed to the type of resin present in the coal matrices and/or differences in the degree of evolution of both coals. The difference in evolution is clearly evidenced by the early generation of coalification products in the form of exudates in TCV, which do no occur in the case of UCV [6]. The perhydrous character of the Jurassic coals is of a post-sedimentary type (i.e. during peatification and/or subsequent coalification processes) and is attributed to the assimilation of highly hydrogenated secondary substances (bituminous and/or oil-like material) from the adjacent organic-rich sedimentary rocks [1], [3] and [6] into their matrices. The sources of hydrogen-rich material were, however, different for each coal. Evidence of incorporation of hydrogen-rich compounds from the primary decomposition of organic material in the sedimentary environment was only clearly established for one of the coals studied, WJV1 [6]. It has also been shown that assimilation into the coal matrices did not take place at the same stage of diagenetic evolution for all the samples. 
The FTIR and Py-GC/MS study [1] showed that the major structural units in these coals are simple phenols with a preponderance of para-alkyl substituted derivatives. From this study it was inferred that perhydrous coals develop a unique evolutionary pathway that differs from the one followed by non-perhydrous coals. However, the effect of the subsequent evolution of a vegetal precursor modified by the presence of terpene-type resin or the incorporation of highly hydrogenated substances during the earlier diagenetic stages of organic evolution can be expected to give rise to differences. In the latter case the nature of such substances as well as the evolutionary stage in which they were assimilated might also affect the transformation of the huminite/vitrinite during the coalification process. As a mean of obtaining data about the irreversible structural modification undergone by the perhydrous vitrinites, analysis of the degradation products by Py-GC/MS is limited because such an analysis focuses on the volatile compounds. By means of Gray-King pyrolysis oil can be recovered for the compositional and structural study of both the volatile and the non-volatile components. This analysis was carried out through a qualitative and quantitative NMR study $\left({ }^{1} \mathrm{H},{ }^{13} \mathrm{C}\right.$ and $2 \mathrm{D}$ proton detected ${ }^{1} \mathrm{H},{ }^{13} \mathrm{C}$ correlation experiments) of the same set of perhydrous coals mentioned above in order to establish accurate oil/vitrinite relationships. Gray-King pyrolysis is justified as a thermal approach for a number of reasons. Such a study has already been preformed on nonperhydrous pure vitrinites and the results obtained have provided relevant information about chemical variability within the vitrinite maceral group [7]. During the pyrolysis of perhydrous coals the tar yields are between 8 and 29\% higher than in non-perhydrous coals [5]. In addition, it has been shown [8] that fragmentation processes prevail over condensation reactions. In the present work evidence showing that tars may be representative of the parent vitrinite is presented. The close resemblance between the FTIR spectra of the oils and those of the raw materials justifies the NMR study. Moreover, the volatile fraction of the oils is made up of the same compounds as those identified by Py-GC/MS and close relationships between NMR and Py-GC/MS have been found.

An exhaustive compositional study of the low-temperature tars is also important from the technological point of view because perhydrous coals are oil-prone materials, which generate oils of a mainly phenolic nature. Phenolic compounds have a peculiar set of chemical properties as a result of which they play a significant role in coal conversion, in particular during liquefaction [9], [10] and [11]. They also have important environmental implications due the toxicity of some phenolic derivatives that could present carcinogenic and mutagenic activity.

\section{Experimental}

Gray-King pyrolysis was performed in accordance with the modification of the standard procedure (ISO 502) described by Suárez-Ruiz et al. [12]. Between 5 and $15 \mathrm{~g}$ of sample with a particle size of $1.0 \mathrm{~mm}$ was placed inside a quartz reactor, $2 \mathrm{~cm}$ in diameter and $25 \mathrm{~cm}$ long. The pyrolysis temperature $\left(550^{\circ} \mathrm{C}\right)$ was reached by heating the apparatus at a rate of 5 and $2{ }^{\circ} \mathrm{C} \mathrm{min}^{-1}$ towards the end of the experiment to reduce thermal inertia. The temperature was controlled by a thermocouple connected to the resistance of the oven. The samples remained under experimental conditions for $2 \mathrm{~h}$. At the end of the process, the solid residues were characterized by measuring the vitrinite reflectance and chemical analysis. The reflectance of the vitrinite was measured on an MPV II Leitz microscope by means of reflected white light using oil immersion objectives $(32 \times)$ in accordance with the ISO $7404 / 5$ procedure. Chemical characterization (proximate and ultimate analyses) was also carried out in accordance with international standard procedures. The elemental analyses were performed by using LECO CHN 600 and LECO SC 132 equipments, and the oxygen was calculated by difference. 
Oil and water were collected in a trap. The oil was separated from the water by decantation and then analyzed by GC/MS, FTIR and NMR. A chromatographic study was carried out using a Hewlett-Packard HP 6890 gas chromatograph equipped with flame ionisation detection (FID). The splitting ratio was 1:24. The detector and injector temperature was $275^{\circ} \mathrm{C}$ and the column temperature was programmed from 50 to $300{ }^{\circ} \mathrm{C}$ at $4{ }^{\circ} \mathrm{C} \mathrm{min}{ }^{-1}$. For the $\mathrm{GC}$ analysis, the samples were dissolved in dichloromethane and kept for a few minutes in an ultrasonic bath to obtain total dissolution; the volume injected was $1 \mu \mathrm{L}$. The compounds were identified by means of GC/MS using a Finningan GCQ gas chromatograph equipped with mass detection. The working conditions were similar to those used in the chromatographic analysis (SE-54 capillary column; detector temperature, $325^{\circ} \mathrm{C}$; injector temperature, $275{ }^{\circ} \mathrm{C}$; column temperature program from 50 to $290{ }^{\circ} \mathrm{C}$ at $4{ }^{\circ} \mathrm{C} \mathrm{min}^{-1}$ ). For FTIR purposes, the oil was dissolved in dichloromethane and dropped gently onto a $\mathrm{KBr}$ pellet. The solvent was caused to evaporate. The NMR spectra were obtained on a Bruker Avance 300 spectrometer equipped with a $5 \mathrm{~mm}$ QNP probe $\left({ }^{1} \mathrm{H},{ }^{15} \mathrm{~N},{ }^{13} \mathrm{C},{ }^{31} \mathrm{P}\right)$. Samples were prepared by dissolving the oils in $\mathrm{CDCl}_{3}$ using TMS as an internal reference. The concentration used was $0.06 \mathrm{~g} \mathrm{~mL}^{-1}$ for ${ }^{1} \mathrm{H}$ NMR and $0.8 \mathrm{~g} \mathrm{~mL}^{-1}$ for ${ }^{13} \mathrm{C}$ NMR. The sweep width was $3000-15,000 \mathrm{~Hz}$ and $128 / 6000-10,000$ transients were collected for the ${ }^{1} \mathrm{H} /{ }^{13} \mathrm{C}$ NMR spectra. The ${ }^{13} \mathrm{C}$ NMR spectra were obtained in the inverse gate-decoupling mode so that they could be subjected to quantitative analysis. This was done to suppress Nuclear Overhauser Effect (NOE) enhancements. In addition, $5 \mathrm{mg}$ of the relaxation agent chromium(III) acetylacetonate $\left(\mathrm{Cr}(\mathrm{acac})_{3}\right)$ was added to reduce the repetition delay to reasonable values (5-10 s). Several control experiments were performed with repetition delays of $25 \mathrm{~s}$ and no noticeable change in the integrals was observed in relation with the spectra obtained with shorter delays. In all cases, a broadening line factor of $2 \mathrm{~Hz}$ was applied before the Fourier transformation. ${ }^{13} \mathrm{C}$ editing of the protonated carbons was achieved through the DEPT pulse sequence, using a 135 proton for polarisation transfer. Quaternary carbon atoms were identified by means of a spin echo experience with an echo delay of $1 / 2(\mathrm{JCH})$. Heteronuclear multiple quantum correlation (HMQC) and heteronuclear multiple bonding correlation (HMBC) experiments including pulse field gradient coherence selection were obtained and processed using standard Bruker software.

\section{Results and discussion}

Except for the WJVh coal which exhibit similar oil and gas productions, perhydrous coals yield more oil than gas (Table 1) upon Gray-King pyrolysis at $550{ }^{\circ} \mathrm{C}$. In all cases, however, both oil and gas productions are higher than those reported for non-perhydrous vitrinites [7]. Compared to the latter, the oil yield for the perhydrous vitrinites studied is between ca. 8 and 29\% higher. The WJVh and WJVl samples show the lowest and highest oil productions, respectively.

Table 1. : Oil and gas productions (\%) in the Gray-King pyrolysis of perhydrous vitrinites

\begin{tabular}{|l|l|l|l|l|l|l|}
\hline & AJV & PGJV & WJVh & WJVI & TCV & UCV \\
\hline Oil (\%) & 23 & 24 & 10 & 31 & 27 & 20 \\
\hline Gas (\%) & 7 & 10 & 10 & 10 & 11 & 11 \\
\hline
\end{tabular}




\subsection{Solid residues}

Table 2 shows vitrinite reflectance and the most significant chemical parameters (volatile matter, carbon, hydrogen and oxygen content and the atomic ratios $\mathrm{H} / \mathrm{C}$ and $\mathrm{O} / \mathrm{C}$ ) for the solid residues obtained after the pyrolysis process. As can be seen, the values of these parameters are relatively similar for all the samples so that the initial differences are lost after heating at $550{ }^{\circ} \mathrm{C}$ by means of Gray-King pyrolysis. Moreover, they are also similar to those found for the pyrolysates derived from non-perhydrous coals [13] suggesting some degree of structural uniformity for all the Gray-King residues. As a result of this, the decrease in volatile matter content and $\mathrm{H} / \mathrm{C}$ atomic ratio is higher for the perhydrous samples than for the nonperhydrous ones, WJVl and WJVh being the perhydrous coals in which these parameters experience the highest and lowest variation, respectively. In general, a higher oil production implies a greater decrease in volatile matter (Fig. 1a). This shows that the release of highly hydrogenated substances in the oils must be the factor mainly responsible for the variations in this parameter with the exception of the WJVh coal. The release of highly hydrogenated substances in the oils should also cause a decrease in the $\mathrm{H} / \mathrm{C}$ atomic ratio. However, there is a lack of correlation between these two parameters (Fig. 1b) with the exception of WJVl. This result suggests there are structural differences between the raw coals as a result of their different degrees of perhydrous character and the different origins of the hydrogen present in the samples.

Table 2. : Vitrinite reflectance and significant chemical parameters for the solid pyrolyzates

\begin{tabular}{|c|c|c|c|c|c|c|}
\hline \multirow[t]{2}{*}{ Vitrinite reflectance (\%) } & AJV & PGJV & WJVh & WJVl & TCV & UCV \\
\hline & 2.46 & 2.52 & 2.45 & 2.50 & 2.48 & 2.51 \\
\hline \multicolumn{7}{|c|}{ Proximate and ultimate chemical analysis ( $\%$, daf) } \\
\hline V.M. & 10.0 & 11.2 & 10.2 & 10.3 & 8.1 & 14.5 \\
\hline $\mathrm{C}$ & 92.0 & 90.8 & 90.4 & 90.2 & 92.8 & 90.3 \\
\hline $\mathrm{H}$ & 3.3 & 3.2 & 2.5 & 3.1 & 2.8 & 2.7 \\
\hline $\mathrm{O}_{\text {diff }}$ & 2.6 & 3.2 & 4.7 & 3.6 & 1.3 & 4.5 \\
\hline \multicolumn{7}{|l|}{ Atomic ratios } \\
\hline $\mathrm{H} / \mathrm{C}$ & 0.43 & 0.42 & 0.34 & 0.41 & 0.36 & 0.36 \\
\hline $\mathrm{O} / \mathrm{C}$ & 0.02 & 0.03 & 0.04 & 0.03 & 0.01 & 0.04 \\
\hline
\end{tabular}



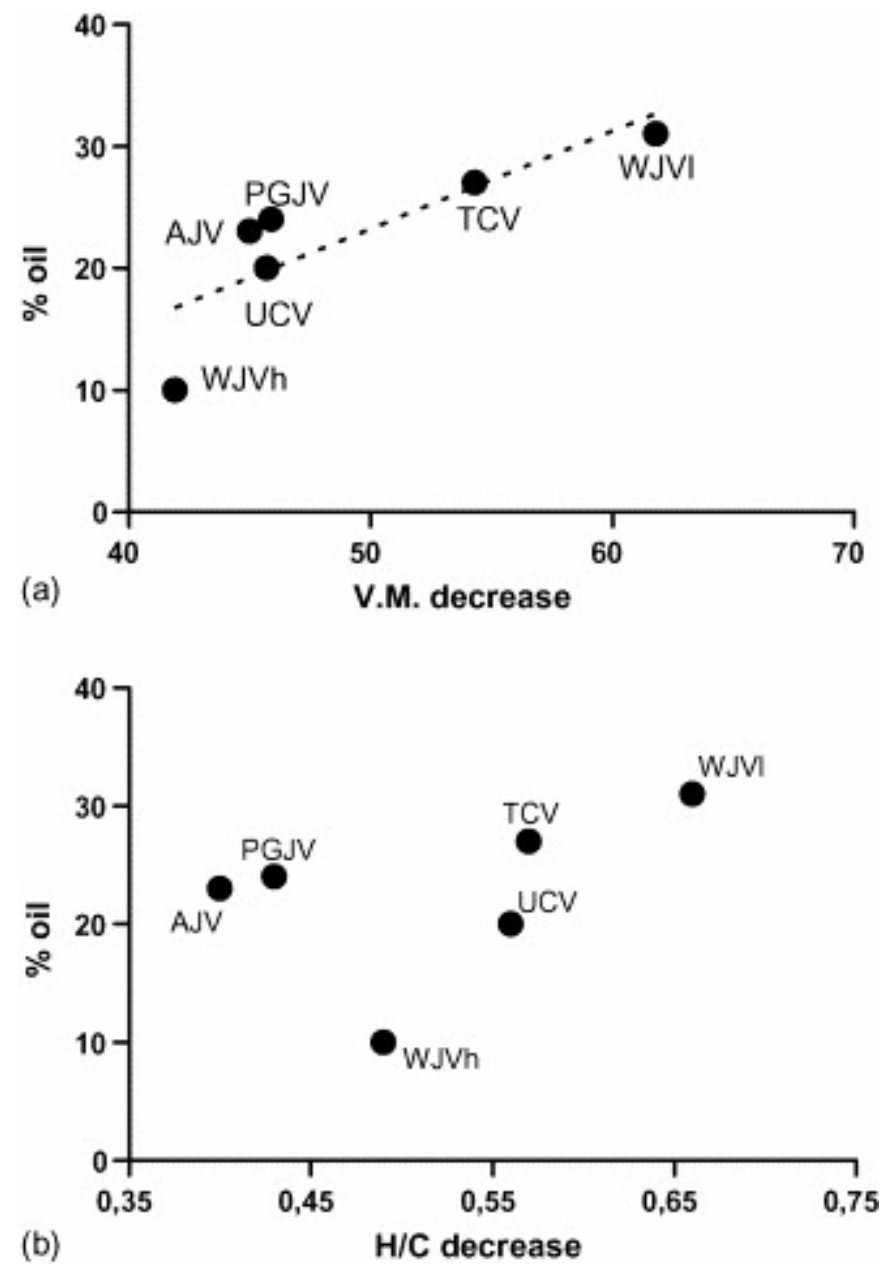

Fig. 1. Relationship between the oil yield and (a) decrease in volatile matter and (b) decrease in atomic ratio $\mathrm{H} / \mathrm{C}$ after the heating of the perhydrous vitrinites at $550{ }^{\circ} \mathrm{C}$.

The less perhydrous character of WJVh coal, which is not apparent from its $\mathrm{H} / \mathrm{C}$ atomic ratio value alone (H/C values for the raw coals: AJV 0.83, PGJV 0.84 and WJVh 0.83) [1] is clearly reflected in the lower oil and gas production, the decrease in volatile matter after heating and the position of this sample in Fig. 1b. For this coal (WJVh) thermal aromatisation/condensation processes are favoured with respect to the other samples. In comparison with AJV and PGJV, a greater aromatisation might be also expected for TCV and UCV which have cycloparaffinic and naphthenic structures in their vitrinite network as a result of the resinization undergone by their botanical precursors. This explains the relative positions of these samples in Fig. 1b. On the other hand, the proximity of AJV and PGJV (Fig. 1b) agrees with several common characteristics previously reported for these samples [1]. In particular, this supports the view that between the two types of non-covalent bonded compounds described for the PGJV [6] coal, those of a more aromatic nature and structurally similar to those assimilated in the coal matrix of the AJV coal are mainly responsible for the perhydrous character of this coal. 


\subsection{Compositional and structural study of the oils: oil/parent vitrinite relationship}

A comparison of the FTIR spectra of the oils and those of the raw materials (Fig. 2) shows there is a close resemblance between them. This confirms the view that the oils released during thermal treatment are made up of similar structural units to those present in the raw materials. Chemical-structural information about perhydrous coals can, therefore, be obtained through the study of the oils. This allows these complex materials to be analysed by means of liquid state techniques, which have clear advantages over characterisation in solid state.
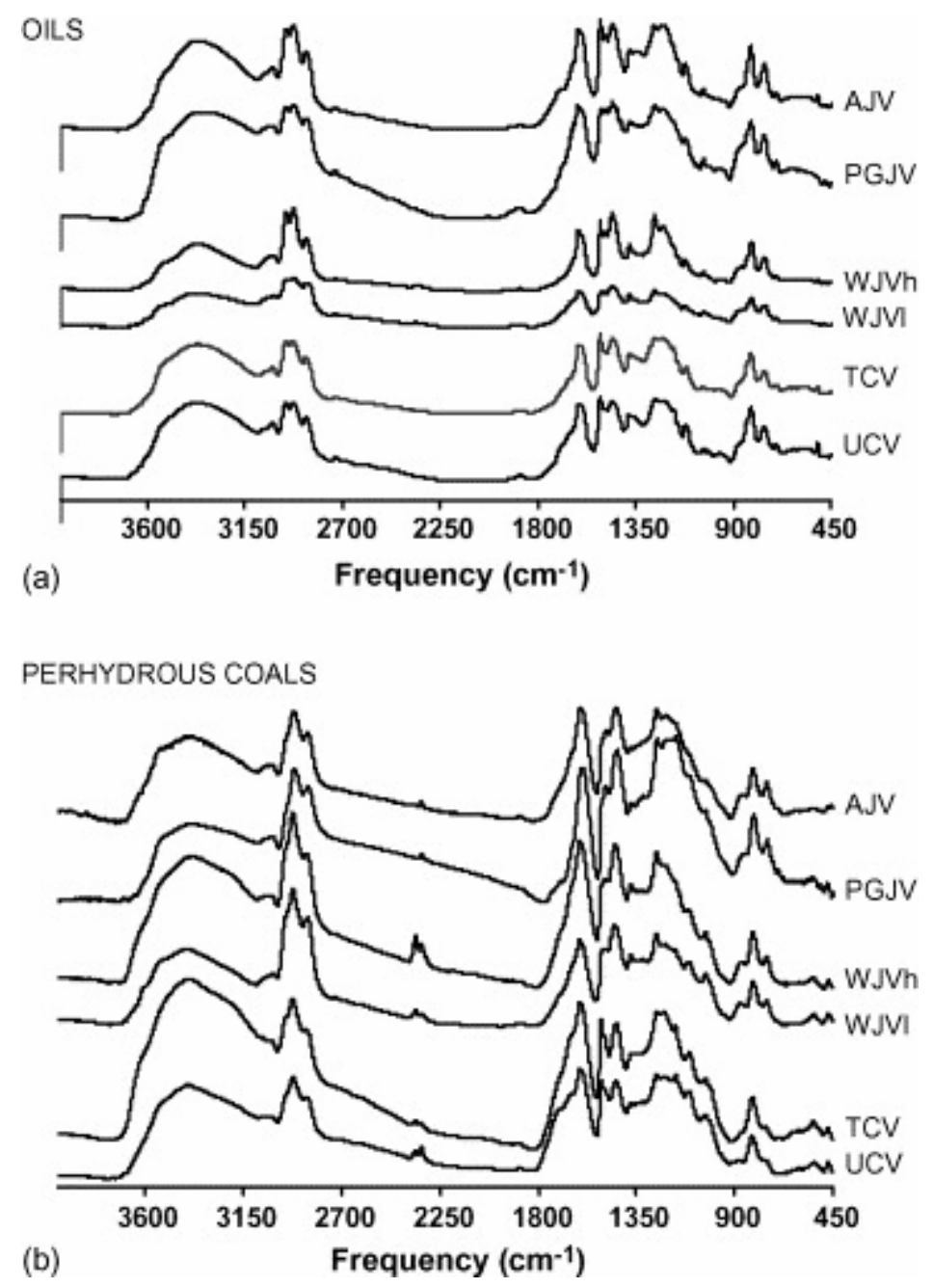

Fig. 2. FTIR spectra of the oils from the perhydrous coals (a) and their comparison with those of the parent coals (b).

\subsubsection{Compositional characteristics of oils}

Fig. 3 shows the chromatograms of the oils and identification of the main compounds is given in Table 3. In the conditions used in this work for the GC/MS analysis some alkylphenol isomers cannot be separated. In these cases the assignment in Table 3 was carried out taking into account the low contribution of the signals corresponding to the structures substituted in the meta position (see the NMR study below). For this reason, the substitution sites of the 
trimethyl- and ethylmethylphenols (peaks N, P and Q, Fig. 3 and Table 3) must be in the ortho and para positions with respect to $\mathrm{Car}-\mathrm{OH}$.
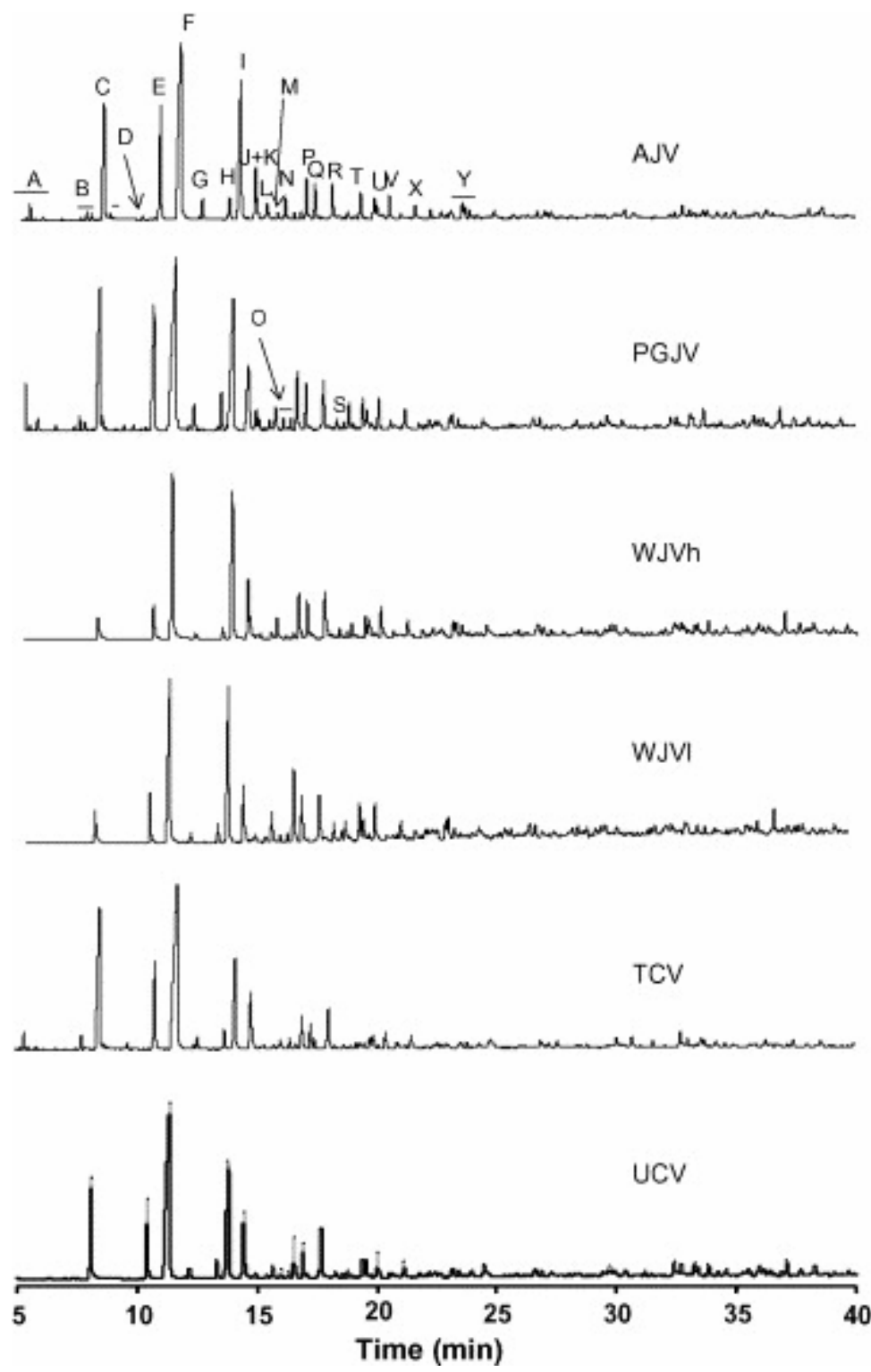

Fig. 3. Gas chromatograms of oils generated by means of the Gray-King pyrolysis of perhydrous vitrinites. For the identification of the peaks see Table 3 .

The compounds with the highest concentration in the mixture are phenols. Among these, phenol and C-1-C-3 alkylphenols are the most abundant. Other compounds also present in the oils but in a low concentration are C-4 alkylphenols, dimethylbenzofurans, naphthalene and the two methylnaphthalene isomers. However the latter (naphthalene and its methyl derivatives) were only clearly detected in the oils derived from the Jurassic samples (AJV, PGJV, WJVh and WJVl). 
Table 3. : Compounds identified by GC/MS (for peak code see Fig. 3)

\begin{tabular}{|c|c|}
\hline Peak code & Peak identification \\
\hline A & Benzene \\
\hline $\mathrm{B}$ & C3-Benzene \\
\hline $\mathrm{C}$ & Phenol \\
\hline $\mathrm{D}$ & Indene \\
\hline $\mathrm{E}$ & $o$-Cresol \\
\hline $\mathrm{F}$ & $p$-Cresol \\
\hline G & 2,6-Dimethylphenol \\
\hline $\mathrm{H}$ & 2-Ethylphenol \\
\hline I & 2,4-Dimethylphenol \\
\hline $\mathrm{J}$ & 4-Ethylphenol \\
\hline $\mathrm{K}$ & 3-Ethylphenol \\
\hline $\mathrm{L}$ & Naphthalene \\
\hline M & Dimethylphenol \\
\hline $\mathrm{N}$ & Trimethylphenol \\
\hline $\mathrm{O}$ & Dimethylbenzofuran + 2-propylphenol \\
\hline $\mathrm{P}$ & Ethylmethylphenol \\
\hline Q & Ethylmethylphenol \\
\hline $\mathrm{R}$ & 4-Propylphenol \\
\hline $\mathrm{S}$ & C4-Phenol \\
\hline $\mathrm{T}$ & 2-Methylnaphthalene \\
\hline $\mathrm{U}$ & C4-Phenol \\
\hline $\mathrm{V}$ & 1-Methylnaphthalene \\
\hline $\mathrm{X}$ & 4-Butylphenol \\
\hline $\mathrm{Y}$ & Dimethylnaphthalene \\
\hline
\end{tabular}

The composition of the volatile fraction of the oils is qualitatively very close to that reported for the products derived from the primary degradation obtained by means of flash-pyrolysis [1]. The major differences reside in the semiquantitative analysis and the lack of traces of alkanes in the oil from WJVl. Such differences can be attributed to the experimental conditions and the accuracy of the integration of some of the peaks in the corresponding chromatograms or fragmentograms. In both cases, the alkylphenols identified are the same as those described by Hatcher et al. for coalified wood [14]. Furthermore, the clear 
preponderance of 2,4-dimethyl- and 4-ethylphenol among the C-2 isomers can be related to the gymnosperm lignin which is essentially composed of guaiacyl structural units [15]. This agrees with the origin of the raw materials, drifted wood, and suggests that the wood precursor belonged to the family of gymnosperm. This kind of plant was abundant during the Mesozoic period to which these coals belong. On the other hand, the detection of only simple phenols in the degradation products and the low values of the vitrinite reflectance for these coals clearly suggest that the structural reorganisation of the aromatic lignin framework was not parallel to the evolution of the oxygenated functionalities.

\subsubsection{Structural characteristics of oils}

Fig. 4 and Fig. 5 show, respectively, the ${ }^{1} \mathrm{H}$ NMR and ${ }^{13} \mathrm{C}$ NMR spectra of the oils. In these figures the different regions considered in this work are depicted and assigned as described previously [7].

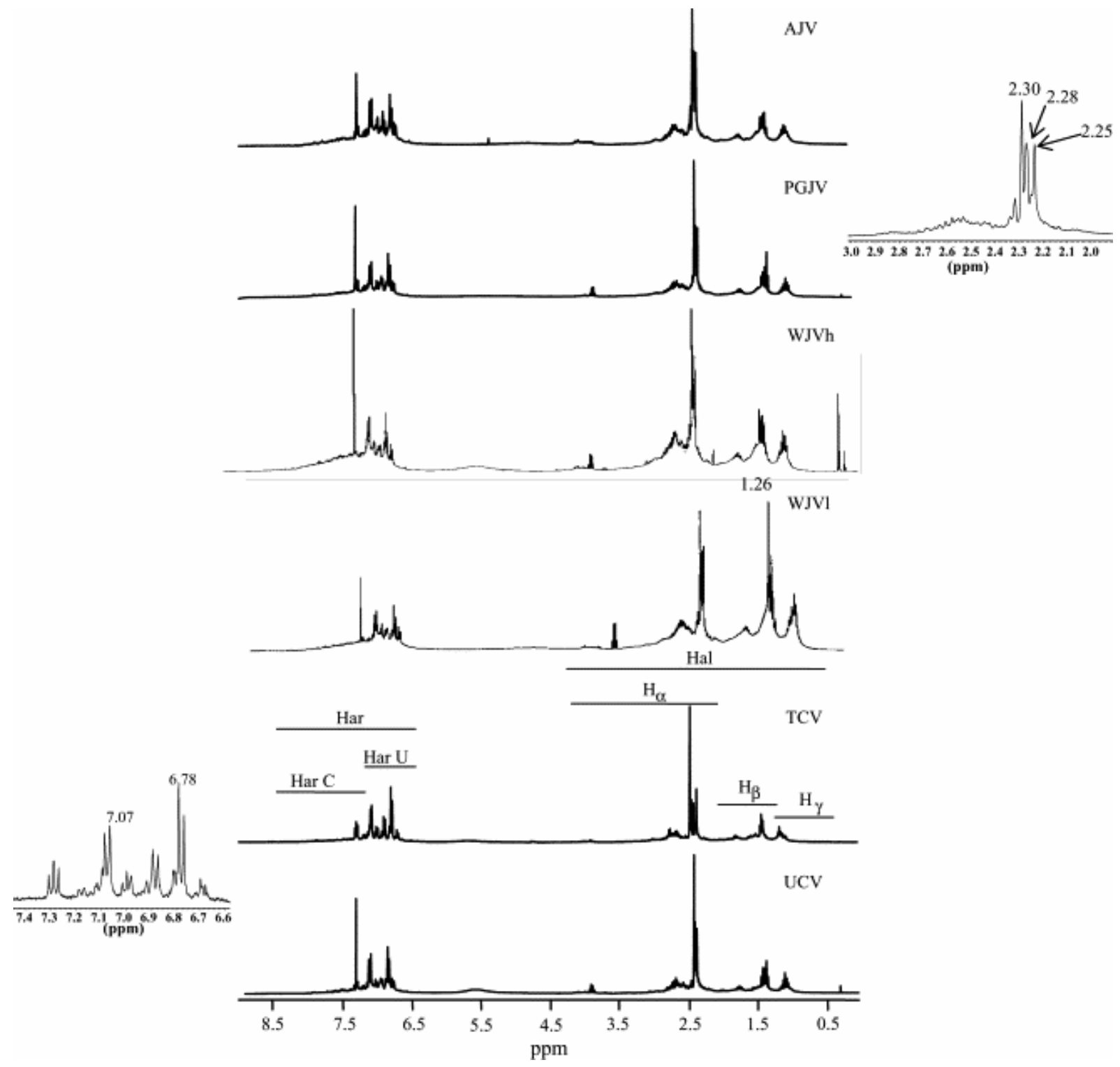

Fig. 4. ${ }^{1} \mathrm{H}$ NMR spectra of the oils generated from perhydrous vitrinites. Extensions of the aromatic (6.4$8.3 \mathrm{ppm})$ and aliphatic $\mathrm{H} \alpha(2.1-4.3 \mathrm{ppm})$ regions with the values of chemical shifts for significant signals are also shown. Har (6.4-8.3 ppm): aromatic protons. HarU (6.4-7.2 ppm): aromatic protons on uncondensed 
structures. HarC (7.2-8.3 ppm) aromatic protons on condensed structures. Hal (0.5-4.3 ppm): aliphatic protons. $\mathrm{H} \gamma(0.5-1.2 \mathrm{ppm}): \mathrm{CH}_{3}$ groups in the $\gamma$ position or even further away from the aromatic ring; methyl groups in naphthenic and/or hydro-aromatic rings. $\mathrm{H} \beta$ (1.2-2.1 ppm): $\mathrm{CH}_{2}$ and $\mathrm{CH}$ groups in $\beta$ position or further away from the aromatic ring (including naphthenic protons) and $\beta \mathrm{CH}_{3} . \mathrm{H} \alpha(2.1-4.3 \mathrm{ppm})$ : protons in $\alpha$ position to the aromatic ring.

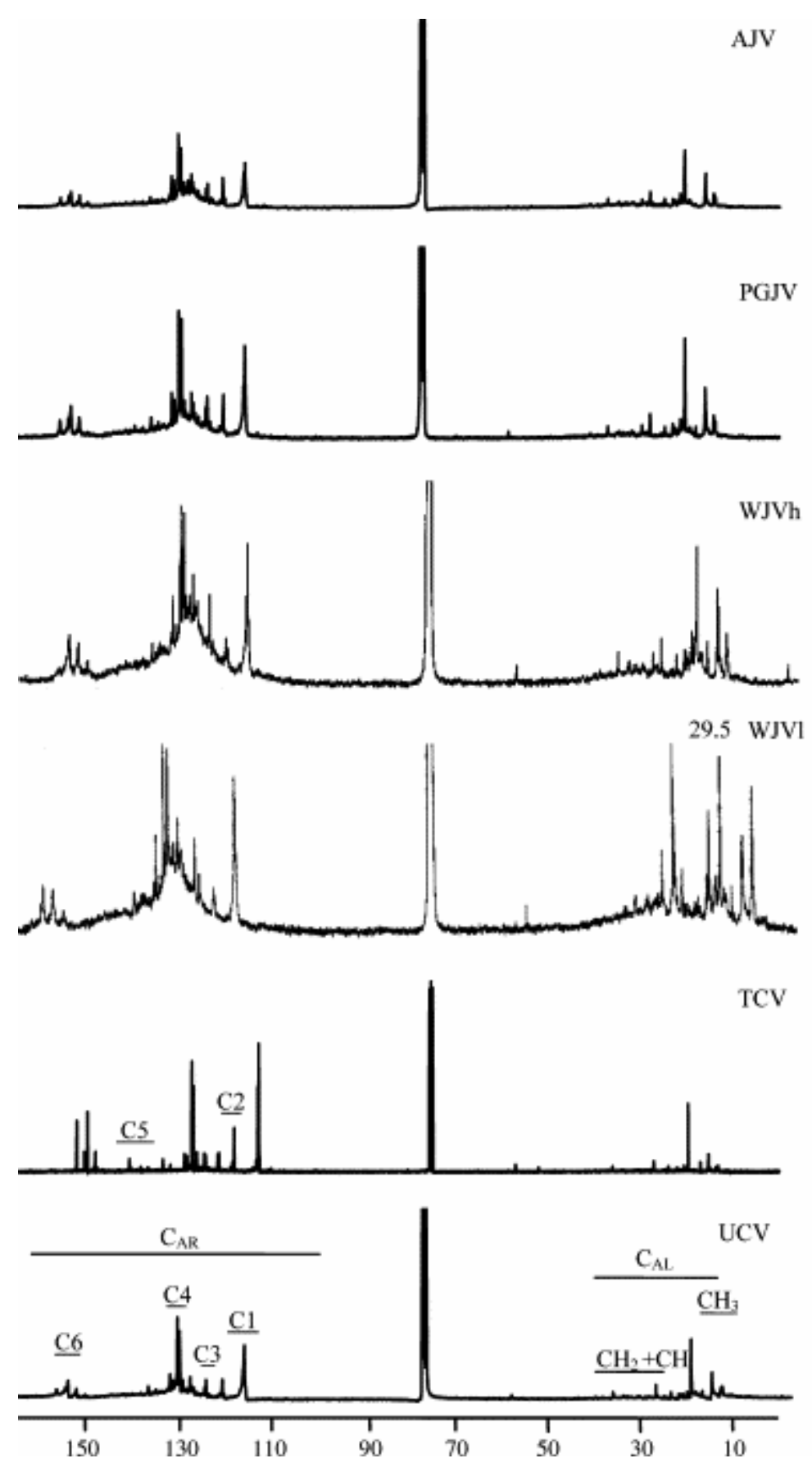

Fig. $5 .{ }^{13} \mathrm{C}$ NMR spectra of the oils generated from perhydrous vitrinites. CAr (110-157 ppm): aromatic carbons. $\mathrm{C} 1$ (110-118 ppm): protonated aromatic carbons ortho to $\mathrm{OH}$ groups. $\mathrm{C} 2$ (118-122 ppm): protonated aromatic carbons para to $\mathrm{OH}$ groups. C3 (122-124 ppm): quaternary aromatic carbons ortho to OH groups. C4 (124133): quaternary and protonated aromatic carbons. $\mathrm{C} 5$ (133-147): quaternary aromatic carbons attached to $\mathrm{CH}_{3}$ groups; in phenols $\mathrm{CH}_{2}(\mathrm{CH})$ para to $\mathrm{OH}$ groups. $\mathrm{C} 6$ (149-157 ppm): ipso-carbon to $\mathrm{OH}$ groups. 
The phenolic nature of the oils is reflected by the resonances in the 149-157 and 110 118 ppm ranges of the ${ }^{13} \mathrm{C}$ NMR spectra (C6 and $\mathrm{C} 1$ regions in Fig. 5), which are assigned to aromatic carbons bonded to oxygen and protonated aromatic carbons ortho to $\mathrm{Car}-\mathrm{OH}$, respectively. The integration of the signals between 149 and $157 \mathrm{ppm}$ relating to the total amount of aromatic carbon was used to estimate the relative amount of phenols in the oils. The linear correlation between the concentration of phenol derivatives in the oils (C6) and the decrease in the $\mathrm{O} / \mathrm{C}$ atomic ratio of the solid after heating shown in Fig. 6 indicates that the release of phenol derivatives is the factor mainly responsible for this decrease. The higher values of $\mathrm{O} / \mathrm{C}$ found for Cretaceous with respect to Jurassic coals must therefore be, due to the higher amount of phenols in the former, with WJV1 coal showing the lowest concentration of phenols.

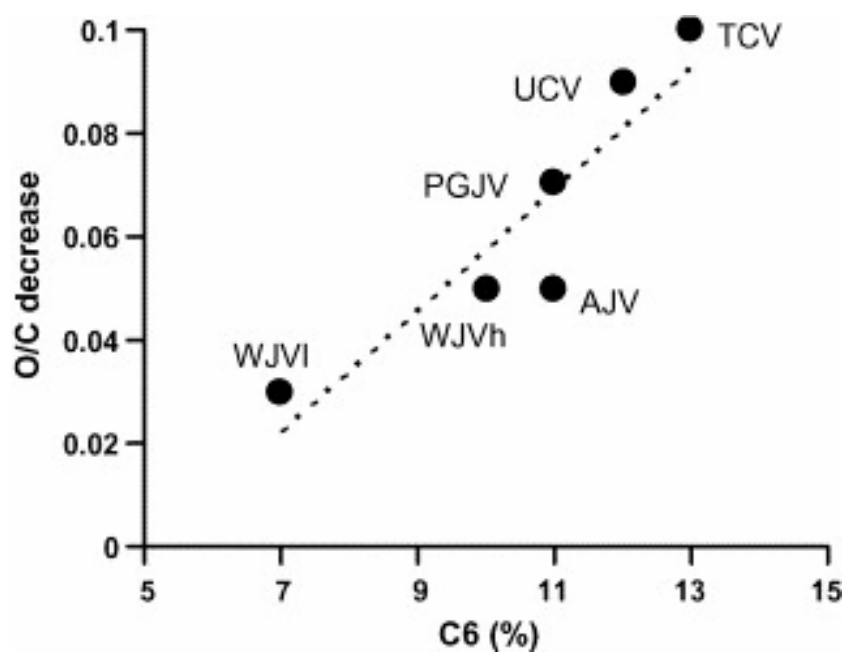

Fig. 6. Correlation between the proportion of aromatic carbon bonded to oxygen and the total aromatic carbon (C6) in the oils and the decrease in the $\mathrm{O} / \mathrm{C}$ atomic ratio in the solid pyrolyzates.

Long chain aromatics were only detected in the WJVl oil and were important contributors to this sample. Methylene groups of long-chain alkyl aromatics are responsible for the sharp signals at $\delta=1.26$ and $29.5 \mathrm{ppm}$ in the ${ }^{1} \mathrm{H}$ NMR and ${ }^{13} \mathrm{C}$ NMR spectra of this oil, respectively, but these signals are absent in the spectra of the other oils (Fig. 4 and Fig. 5). This again confirms the different nature of the compounds assimilated in the WJVl coal as well as its strong perhydrous character. The presence of alkyl aromatics with a relatively long chain in WJVl is the result of the incorporation of hydrogen-rich compounds from the primary decomposition of organic material in the sedimentary environment in which the organic remains were deposited. The assimilated compounds, may be a source of fatty acids and alcohol which are thought to have reacted with lignin to yield long-chain alkyl aromatics [16].

The highly aliphatic nature of WJVl is also reflected in the low values of aromatic hydrogen and the carbon aromaticity of its oil (Fig. 7). In this figure, the hydrogen and carbon aromaticity values of the raw coal and oil are compared. As can be observed, there is a clear interrelation between the aromaticity of the oil and its parent coal (Fig. 7a). However, this was not the case for aromatic hydrogen (Fig. 7b). TCV and UCV are characterized by a higher amount of aromatic hydrogen than the AJV, PGJV and WJVh oils even though the opposite was the case for the raw coals. Except for the WJVl oils that contain a significant amount of long-chain alkyl aromatics, aliphatic structures in oils arise from short alkyl substituents. This 
is evidenced by the preponderance of signals caused by the $\mathrm{CH}_{3}$ groups directly bonded to an aromatic ring (2.1-2.4 ppm, Fig. 4) and mainly due to the methyl groups in the phenol derivatives. The most intense signals in this region resonate at $2.30,2.28$ and $2.25 \mathrm{ppm}$. These signals correlate (Fig. 8a) with the carbon atoms at $20.1\left(\mathrm{CH}_{3}\right.$ para to $\left.\mathrm{Car}-\mathrm{OH}\right), 15.6$ and $15.5 \mathrm{ppm}\left(\mathrm{CH}_{3}\right.$ ortho to $\left.\mathrm{Car}-\mathrm{OH}\right)$. The assignments of the relative position of these methyl groups with respect to the $\mathrm{Car}-\mathrm{OH}$ were carried out in accordance with the chemical shifts of the major compounds present in the volatile fraction, $p$ - and $o$-cresol and 2,4-dimethylphenol and the HMBC spectra (Fig. 8b). The lack of correlation between the aromatic hydrogen in the oil and its parent coal must be due to differences in the aromatic substitution of the samples and to structural differences in the aliphatic moieties of the parent coals [1], which would imply a different behaviour upon heating.
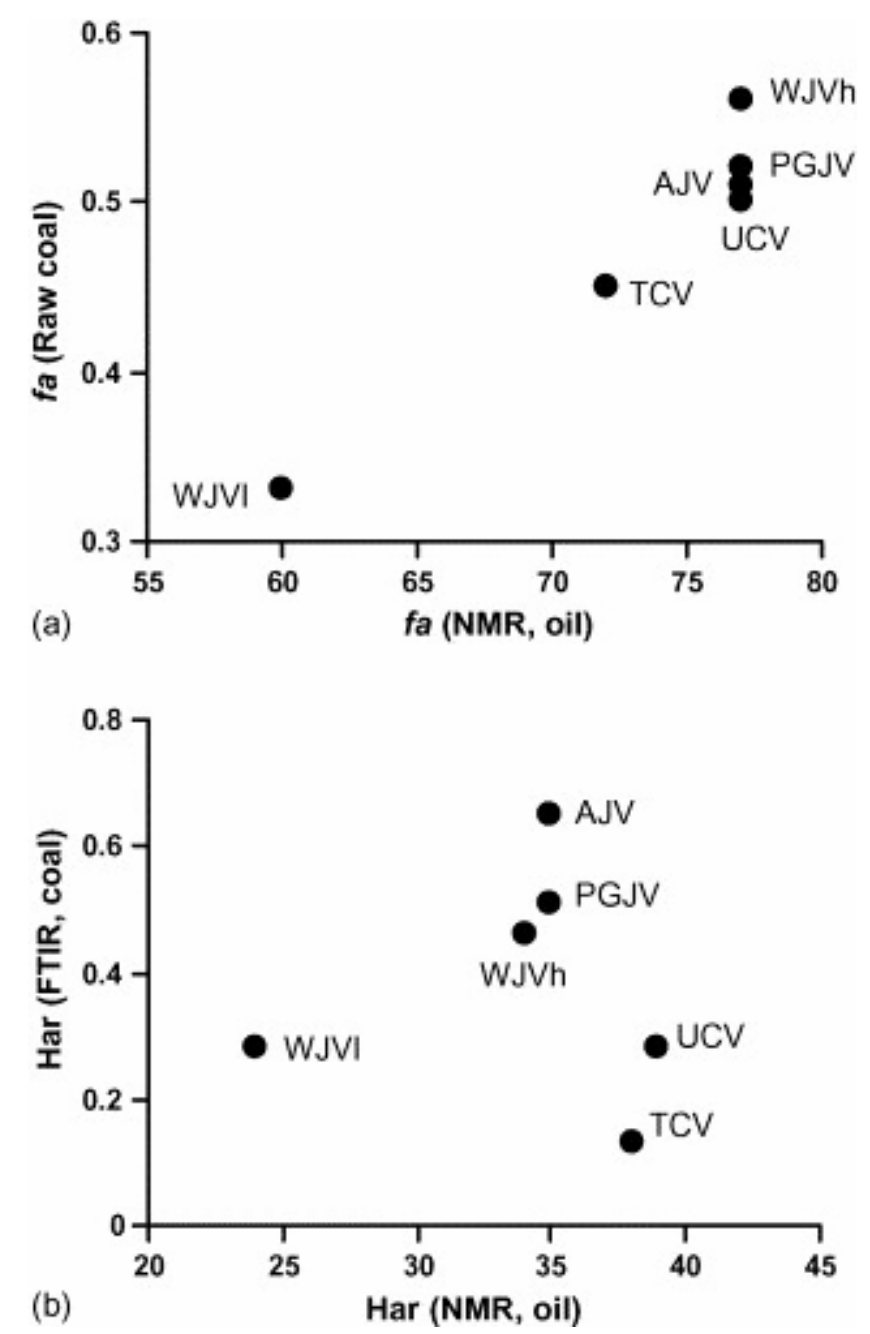

Fig. 7. Comparison of values of aromaticity (a) and aromatic hydrogen for the parent coals and the oils (b). 


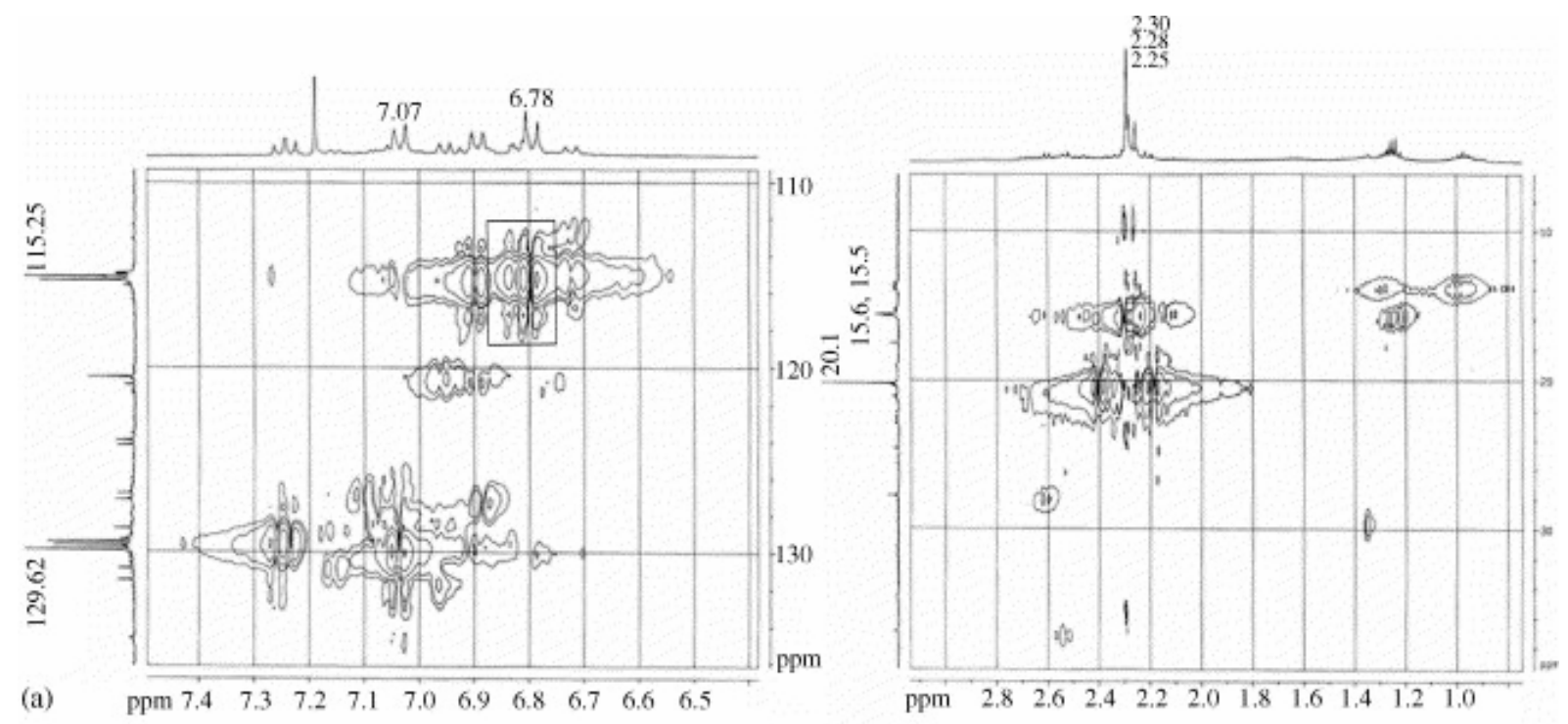

(a)
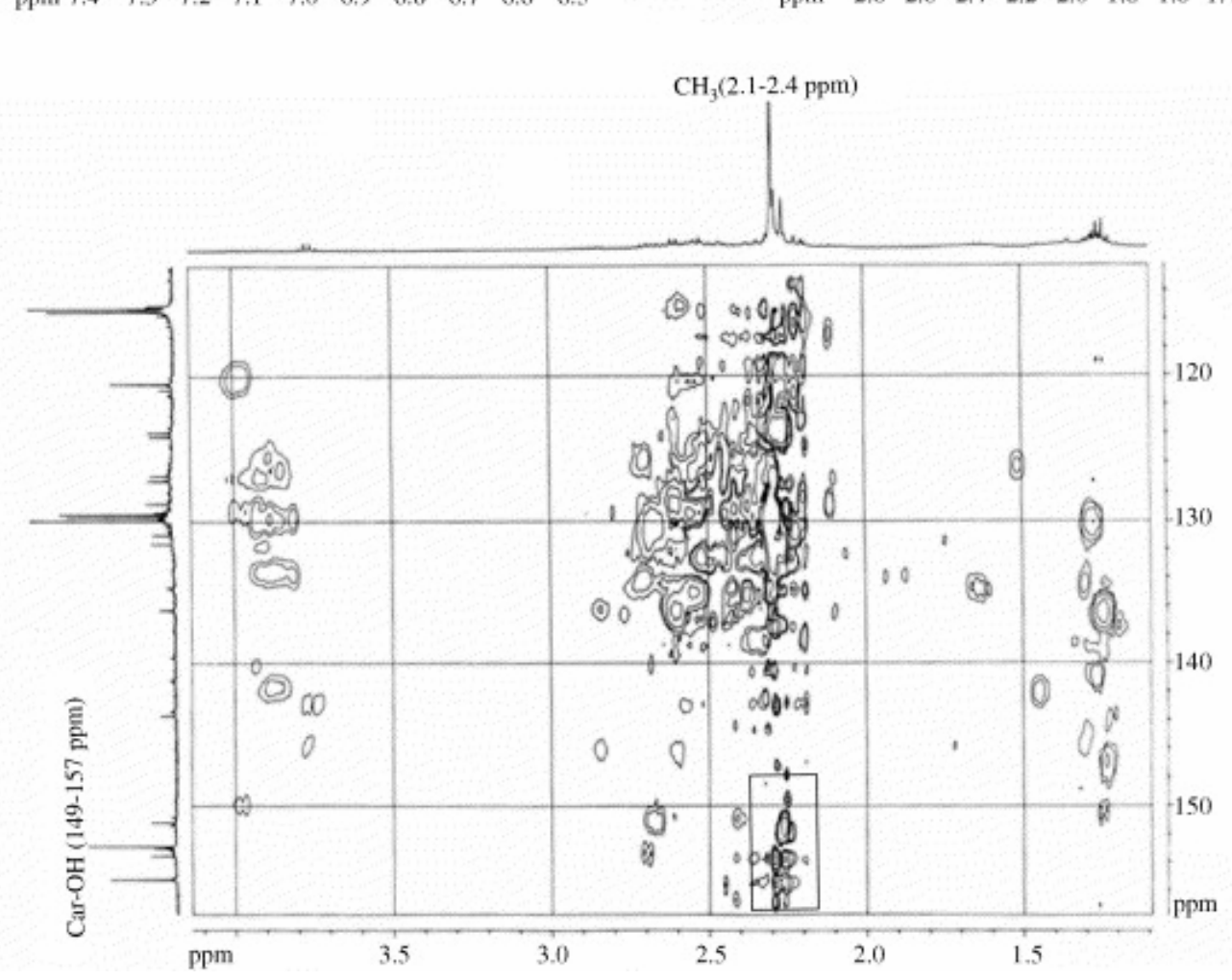

(b)

Fig. 8. HMQC (a) and HMBC (b) spectra for TCV oil as an example.

The degree of substitution of the aromatic structures present in the oils was estimated through the Har/Car values. This parameter shows a good linear correlation with the proportion of phenol and cresol to C2-C4 alkyl phenol ratio (Py-GC/MS) (Fig. 9). The NMR data of the oils are again consistent with the results obtained by means of flash pyrolysis [1]. Moreover, the results obtained suggest that the higher amount of aromatic hydrogen in TCV and UCV with respect to AJV, PGJV and WJVh is due to the lower substitution of phenol derivatives. 


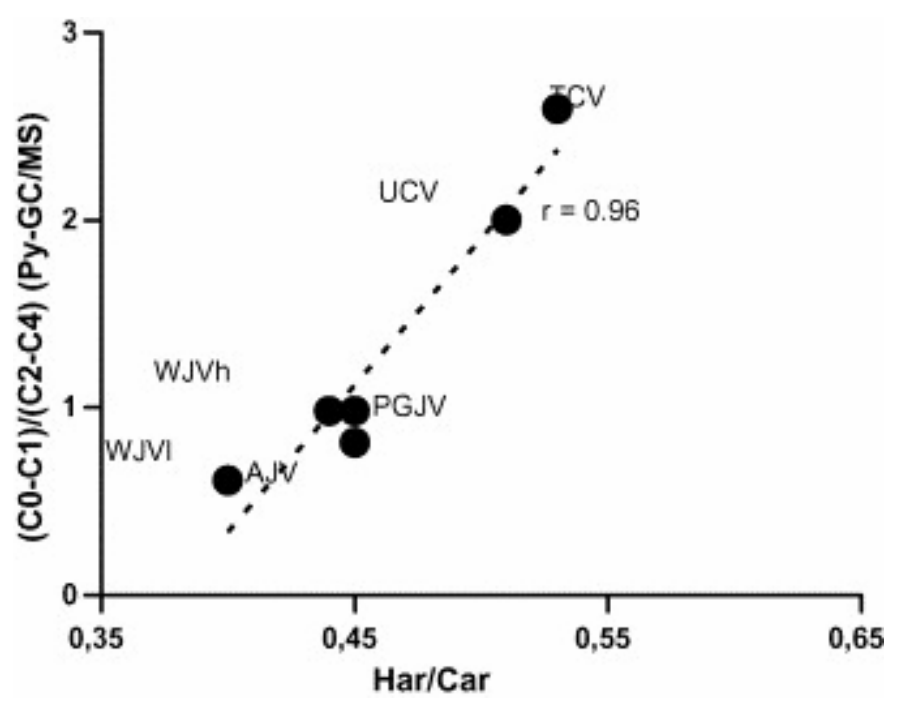

Fig. 9. Correlation of the proportion of phenols and cresols to the $\mathrm{C} 2-\mathrm{C} 4$ alkyl phenol ratio deduced by PyGC/MS and the degree of substitution of the aromatic units in the oils estimated by the NMR Har/Car ratio.

The range of aromatic protons indicates that they mainly belong to mono- and di-aromatic structures (6.4-7.2 and 7.2-8.5 ppm, respectively). The preponderance of para-substitution is reflected in the ${ }^{1} \mathrm{H}$ NMR spectra (Fig. 4) through two prominent multiplets centred at 7.07 and $6.78 \mathrm{ppm}$ with a multiplicity pattern corresponding to an $\mathrm{AA}^{\prime} \mathrm{XX}^{\prime}$ spin system. The HMQC spectrum (Fig. 8a) shows cross peaks between these protons and carbons at 115.25 and $129.62 \mathrm{ppm}$, respectively. The chemical shifts of the signals agree with those of $p$-cresol, the major contributor to the volatile fraction of the oils and with the degradation products obtained by flash pyrolysis. Such multiplets are chiefly responsible for the aromatic protons in the 6.2-7.2 ppm region (HarU), which explains the correlation between the contribution of para-cresol to the amount of phenols, estimated through Curie point Py-GC/MS, and the proportion of aromatic protons on uncondensed structures, HarU (Fig. 10a).

Although the degradation products obtained by means of Py-GC/MS are mainly phenolic they also contain aromatic hydrocarbons [1]. Such hydrocarbons are most probably responsible for the aromatic signal in the 7.2-8.5 ppm range in the ${ }^{1} \mathrm{H}$ NMR spectra of the oils (HarC, Fig. 4). In fact, the proportion of condensed aromatic hydrocarbons estimated through Py-GC/MS and the HarC values follows a similar trend (Fig. 10b). 

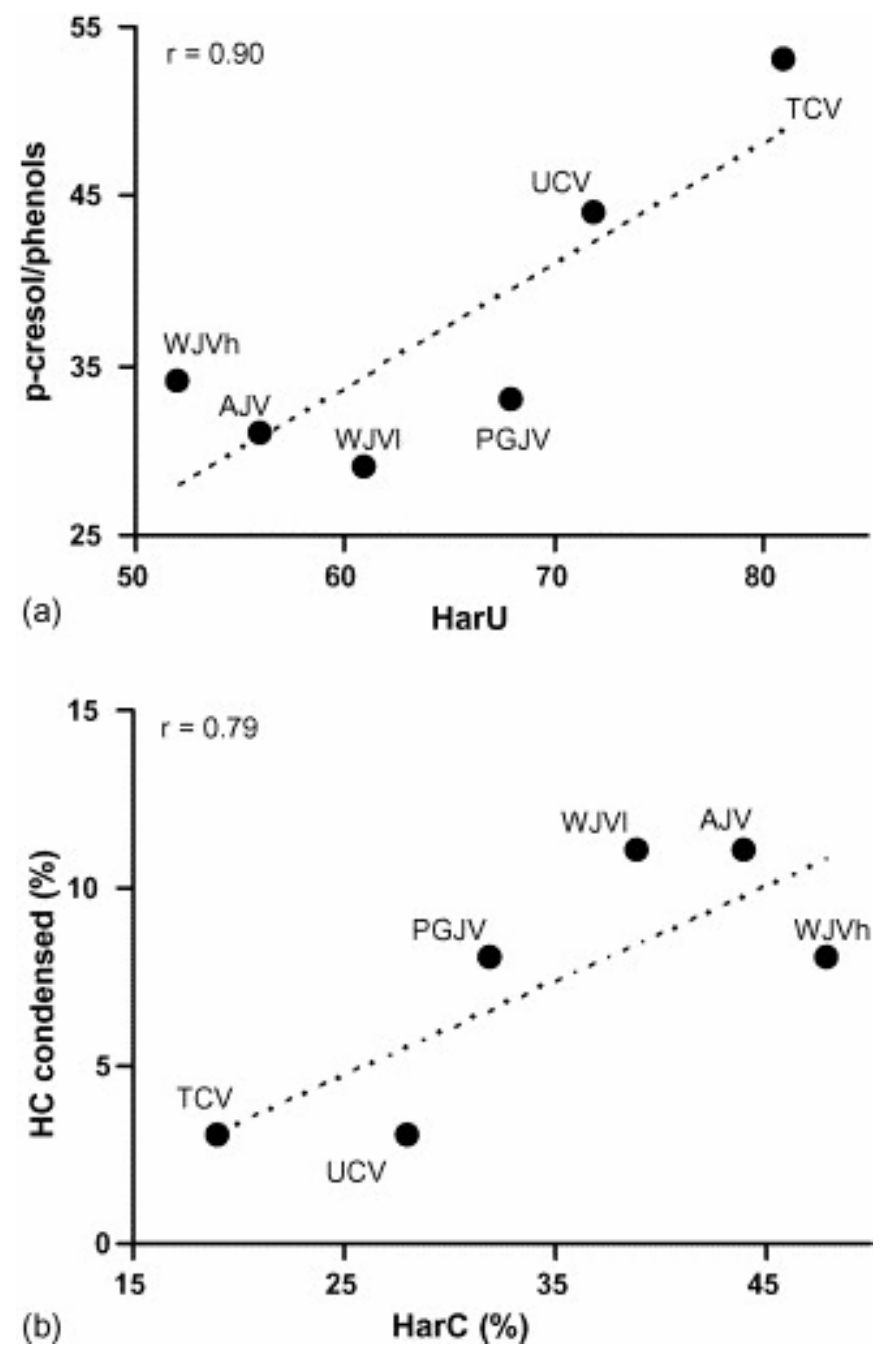

Fig. 10. Relationships between: (a) proportion of aromatic protons on uncondensed structures (HarU, as a percentage to the total amount of aromatic protons) present in the oils generated at $550{ }^{\circ} \mathrm{C}$ by means of GrayKing pyrolysis and the contribution of $p$-cresol to the total amount of phenols estimated through Py-GC/MS; (b) proportion of condensed aromatic hydrocarbons in the degradation products of perhydrous vitrinites estimated by means of Py-CG/MS and the HarC (percentage in relation to the total amount of aromatic protons) values deduced through the ${ }^{1} \mathrm{H}$ NMR spectra of Gray-King oils.

The preponderance of para-substituted phenols in the oils extended to the whole coal, which explains the particular features found in the FTIR in relation to the aromatic structures, i.e. the anomalous distribution of the aromatic hydrogen in the raw coals with a preponderance of the $815 \mathrm{~cm}^{-1}$ mode in the aromatic $\mathrm{C}-\mathrm{H}$ out of plane bending modes and the absorption band at $1500 \mathrm{~cm}^{-1}$. Furthermore, structural data for both oils and whole coals show a higher preponderance of such structures in the Cretaceous than in the Jurassic samples. Thus, a good correlation between HarU and \%815 was found (Fig. 11a). On the other hand, the NMR study of the Gray-King oils shows a higher preponderance of ortho substitution for the Jurassic samples than for the Cretaceous ones. This is inferred from the relative intensity of the signals due to $\mathrm{CH}_{3}$ ortho to the $\mathrm{Car}-\mathrm{OH}$ at ca. $15 \mathrm{ppm}$ (Fig. 5). Furthermore, oils derived from the Jurassic coals show lower (higher) $\mathrm{C} 1$ and $\mathrm{C} 2$ (C3) values than oils derived from the Cretaceous samples (Fig. 11b). This result may again be extrapolated to the whole coal and explain the higher proportion of ortho-disubstituted aromatic rings in the Jurassic with respect 
to Cretaceous coals, as estimated from the relative intensity of the infrared mode at $750 \mathrm{~cm}^{-1}$ (Fig. 11b).

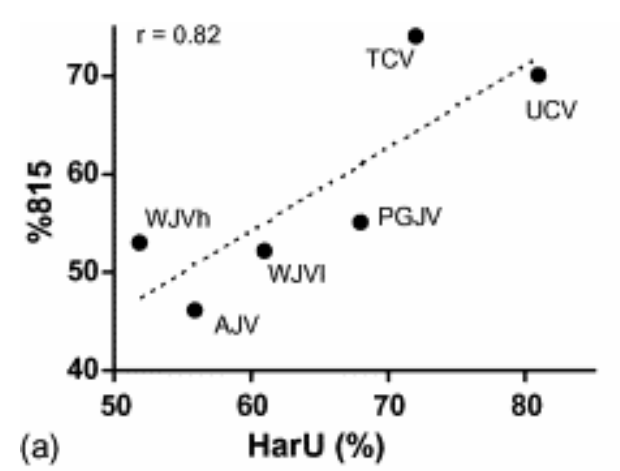

(b)

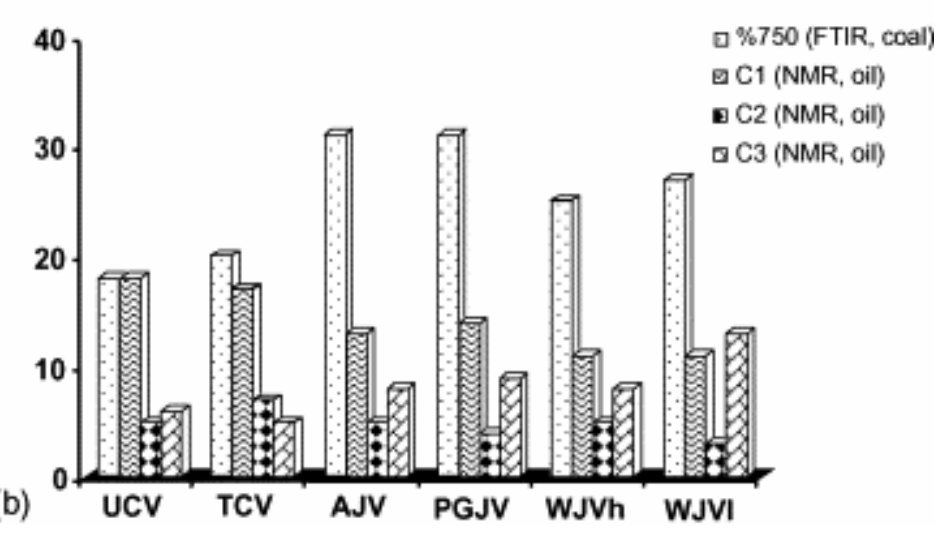

Fig. 11. (a) Correlation between HarU (from NMR of Gray-King oils) and \%815 (from FTIR, raw coals). (b) Comparison of the ${ }^{13} \mathrm{C}$ NMR data for the oils (regions $\mathrm{C} 1, \mathrm{C} 2$ and $\mathrm{C} 3$, values of the integrated area in relation to the total amount of aromatic carbon) and the FTIR index, \%750, for the parent vitrinites.

A comparison of the aromatic region in the ${ }^{13} \mathrm{C}$ NMR spectra of the oils derived from perhydrous and non-perhydrous coals (Fig. 12) shows that the distribution pattern of phenol derivatives differs. Because the composition of the generated oils depends on the rank and maceral composition of the vitrinite of the raw coals [7], the oil derived from a nonperhydrous coal of a subbituminous/high volatile bituminous coal rank (FV coal) mainly composed of telinite (more structured material) [5] was chosen for the comparison. 


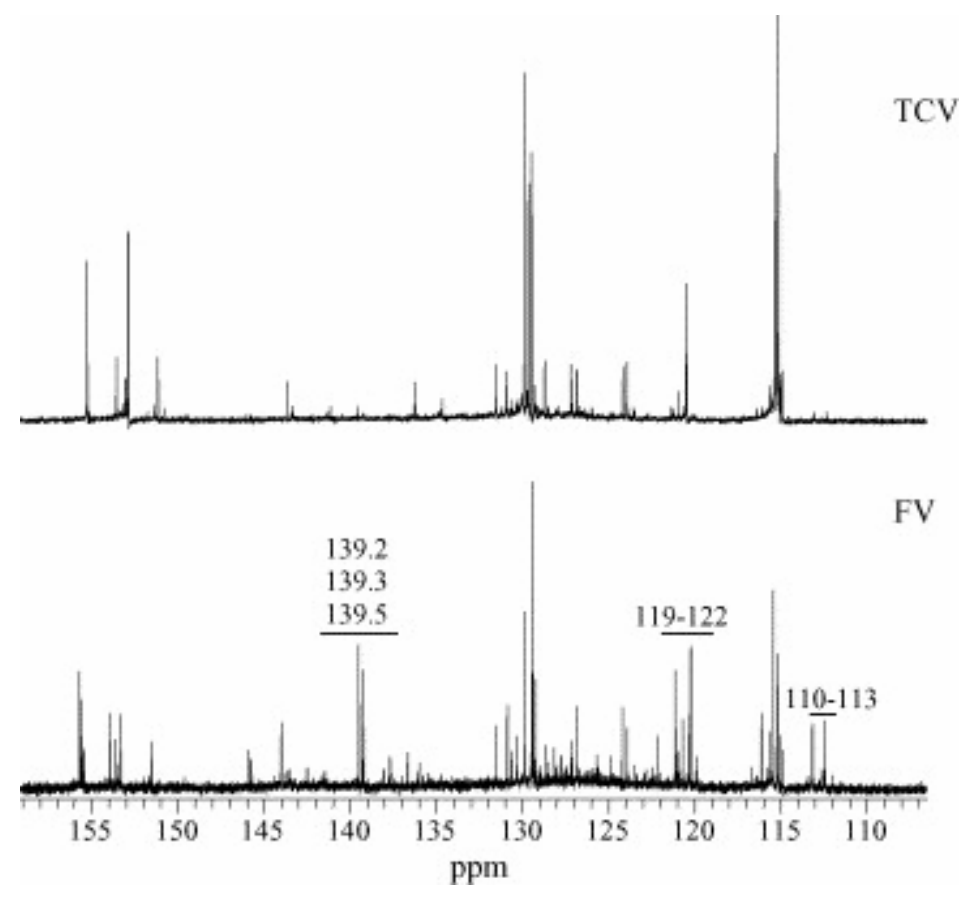

Fig. 12. Comparison between the aromatic region of the ${ }^{13} \mathrm{C}$ NMR spectra of oils derived from perhydrous and non-perhydrous coals (TCV and FV, respectively are taken as examples) showing the different distribution patterns of phenolic compounds.

As can be observed in Fig. 12, the C1 region (110-118 ppm), attributed to ortho to Car-OH protonated carbons, shows two groups of signals (110-113 and 114-118 ppm) for the oils from non-perhydrous coals. The signals between 110 and $113 \mathrm{ppm}$ indicate that an alkyl group is substituting the para position of the Car-H, i.e. alkyl group meta to the Car-OH. In the oils from the perhydrous coal this group of signals is absent. The ${ }^{13} \mathrm{C}$ NMR of these oils do not show resonances at $139 \mathrm{ppm}\left(\mathrm{Car}-\mathrm{CH}_{3}\right.$ meta to $\left.\mathrm{Car}-\mathrm{OH}\right)$ but in the oils derived from non-perhydrous coals three clear signals at 139.2, 139.3 and $139.5 \mathrm{ppm}$ can be observed. The spin echo and DEPT experiments show that, for the oils derived from the perhydrous coals, the signals in the $\mathrm{C} 2$ region (119-122 ppm) correspond to protonated aromatic carbons due to Car-H para to Car-OH. However, in this region the oils from the non-perhydrous coals also show quaternary carbons (signal at $120.8 \mathrm{ppm}$ for the FV oil, Fig. 12). Such a resonance may be attributed to $\mathrm{Car}-\mathrm{CH}_{3}$ ortho to $\mathrm{Car}-\mathrm{OH}$ in 2-methyl-5-alkylphenols [7].

From the above discussion it can be concluded that in oils derived from non-perhydrous coals the ortho-, meta- and para-substituted phenolic compounds are present, but in those derived from perhydrous coals the meta isomers are almost entirely absent. In the latter, the sites of alkyl-substitution are those inherited from the lignin precursors, the 2 and 4 positions. The results obtained suggest that the evolution of their perhydrous vitrinite took place not only with a minimal disruption of the three dimensional networks inherited from the lignin but also that the structural reorganization of the lignin framework associated with additional carbon substitution was limited. Studies on coalified wood [17] as models for the normal evolution of vitrinite show that coalification up to the subbituminous coal rank does not produce any notable disruption of the macromolecular structure of the lignin. However, an increase in carbon substitution takes place early, during the transformation to lignite. 
Structural differences of the aliphatic moieties present in the TCV coal with respect to the others were previously inferred [1] and [6]. The distribution of the aliphatic carbon of the oils provides new data concerning these differences. Except for WJVl oil and as a result of the presence of long-chain alkyl aromatics, TCV is the only oil with a high amount of carbons due to the $\mathrm{CH}_{2}$ and $\mathrm{CH}$ groups. This oil also shows a relatively low proportion of signals in the 18-23 ppm region (A region). Fig. 13 exhibits a clear interrelation between the intensity of the aliphatic $\mathrm{C}-\mathrm{H}$ stretching modes in the FTIR of the raw coal and the proportion of methyl groups in the mentioned region of the ${ }^{13} \mathrm{C}$ NMR spectra.

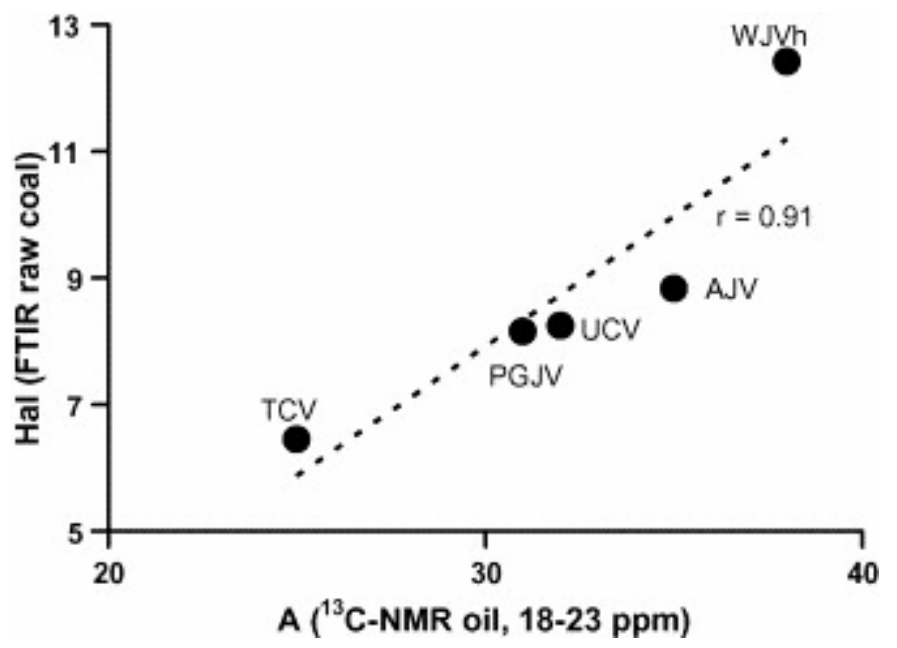

Fig. 13. Correlation between the intensity of the infrared modes due to aliphatic $\mathrm{C}-\mathrm{H}$ stretching vibrations (3000-2700 $\mathrm{cm}^{-1}$ ) for the UCV, TCV, AJV, PGJV and WJVh raw coals and the integration values for the carbon resonances in the $18-23 \mathrm{ppm}$ range (A region) of the ${ }^{13} \mathrm{C}$ NMR spectra of the corresponding oils.

The NMR study of the Gray-King oils only provides evidence of the incorporation of lipoidal material in the WJV1 coal. This incorporation is responsible for the high perhydrous character of WJVl. For the other Jurassic coals (AJV, PGJV and WJVh), the results obtained indicate that the structure of the vitrinite may be ascribed to that of the vitrinite models in the range of subbituminous coal rank. However, the structural reorganization of the lignin framework associated with additional carbon substitution is limited. The small size of the aromatic units with a low degree of substitution contributes to the peculiar properties of these coals. This is explained by the presence of secondary substances (aromatic and polar compounds) which enhance the hydrogenation processes, thus hindering the cross-linking and condensation reactions typical of the transit from subbituminous to bituminous coal rank and leading to vitrinite reflectance suppression. This is of particular significance in AJV and PGJV in which these secondary substances occupy the close porosity of the ulminite, which explains the unusually high difference between the reflectance of the ulminite $(0.39$ and $0.35 \%$, for AJV and PGJV, respectively) and phlobaphinite (AJV 0.72\% and PGJV 0.51\%).

Despite the low hydrogen aromaticity of the TCV and UCV coals, the compositional and structural studies do not show products that suggest the incorporation of lipoidal material. Moreover, although the properties of the vitrinite in these coals are affected by the presence of resinite, the failure to detect in the degradation products of compounds related to the presence of this component clearly points to the importance of the distribution of resinite and huminite/vitrinite and their interrelation for the properties of TCV and UCV. The data relating to the whole coal and those obtained through pyrolysis techniques agree with a process of 
resinization that differs from the presence of resinous material dispersed in the huminite and acting as a mobile phase reported as the origin of the perhydrous character and vitrinite reflectance suppression in some coals [18]. The substances responsible for the low aromaticity in these coals must be covalently bonded to the vitrinite network. A possible explanation is the incorporation of aliphatic structures via intramolecular covalent linkages, such as sulphur or oxygen bonds [19]. The relatively low sulphur content $(2.3 \%)$ of the TCV and UCV coals, excludes the incorporation of aliphatic structures via sulphur linkages. However, the incorporation of aliphatic structures through covalent oxygen linkages may be possible. The structural units for these coals may therefore be a mixture of $p$-alkyl phenols like the structural units proposed earlier [1] and $p$-alkyl alkyloxybenzenes. Both types of structures may yield phenols upon heating. The incorporation may compete favourably with the process associated with aromatisation and/or condensation of the vitrinite network, which is mainly responsible for the increase in vitrinite reflectance. Furthermore, a significant cycloparaffinlike nature for the aliphatic moieties incorporated to the huminite/vitrinite might be expected because they proceed from terpene-type resins. The hydrogen-donor character of this kind of structures might be expected to affect the irreversible physico-chemical changes described during the earlier stages of the coalification process (decarboxylation, dehydroxylation, demethylation and aromatisation) to different extents. In particular, an enhancement of the $O-$ demethylation reactions to give phenols in the presence of hydrogen-donor compounds might take place [20] and [21]. As a result, the evolutionary pathway for the coals studied here differs from that of non-perhydrous coals and other coals affected by a hydrogen-enrichment of different origin.

\section{Conclusions}

The results obtained show the important role of the process of hydrogen donation and transfer in explaining the anomalies of the vitrinite reflectance values in the perhydrous samples. Furthermore, they also reflect clear differences in the mechanisms involved in vitrinite reflectance suppression depending on the origin of the perhydrous character of the coals. The incorporation of aliphatic structures via covalent oxygen linkages for the coals in which the vegetal precursors of vitrinite have been modified by terpene-type resin saturation, also competes with the typical processes responsible for the increase in reflectance. In coals affected by the impregnation of oil/petroleum-like products, the nature of the assimilated substances must be taken into account in order to establish an accurate mechanism to explain vitrinite reflectance suppression. Cross-linking and condensation are hindered mainly when the assimilated substances are predominantly aromatic and polar in nature. The incorporation of a large amount of lipoidal material, however, seems to affect the development of reflectance in a different way. Both processes avoid the usual increase in vitrinite reflectance during the coalification processes of coals, which renders it useless as a tool for determining the rank of this type of coals.

\section{Acknowledgements}

The financial support for this work was provided through a contract with the European Community (No. 7220/EC-769). The authors thank the NMR facilities of the University of Almería (Spain) for allocating measuring time. 


\section{References}

[1] M.J. Iglesias, J.C. del Río, F. Laggoun-Défarge, M.J. Cuesta and I. Suárez-Ruiz, J. Anal. Appl. Pyrolysis 62 (2002), p. 1.

[2] Suárez-Ruiz, A. Jiménez, F. Iglesias, J.G. Laggoun-Défarge and J.G. Prado, Energ. Fuels 8 (1994), p. 1417.

[3] I. Suárez-Ruiz, M.J. Iglesias, A. Jiménez, F. Laggoun-Défarge, J.G. Prado, in: P.K. Mukhopadhyay, W.G. Dow (Eds.), Vitrinite Reflectance as a Maturity Parameter. Applications and Limitations, Proceedings of the ACS Symposium Ser., col 570, American Chemical Society, Washington, DC, 1994, p. 76.

[4] M.J. Iglesias, A. Jiménez, F. Laggoun-Défarge and I. Suárez-Ruiz, Energ. Fuels 9 (1995), p. 458.

[5] A. Jiménez, M.J. Iglesias, F. Laggoun-Défarge and I. Suárez-Ruiz, Chem. Geol. 150 (1998), p. 197.

[6] M.J. Iglesias, J.C. del Río, F. Laggoun-Défarge, M.J. Cuesta and I. Suárez-Ruiz, J. Anal. Appl. Pyrolysis 68/69 (2003), p. 387.

[7] M.J. Iglesias, M.J. Cuesta and I. Suárez-Ruiz, J. Anal. Appl. Pyrolysis 58/59 (2000), p. 255.

[8] A. Arenillas, F. Rubiera, J.J. Pis, M.J. Cuesta, M.J. Iglesias, A. Jiménez and I. SuárezRuiz, J. Anal. Appl. Pyrolysis 68/69 (2003), p. 371.

[9] Z. Abdel-Baset, P.H. Given and F. Yarzab, Fuel 57 (1978), p. 95.

[10] K. Erdamnn, T. Mohan and J.G. Verkade, Energ. Fuels 10 (1996), p. 378.

[11] E. Furimsky, L. Vancea and R. Belanger, Ind. Eng. Chem. Prod. Res. Dev. 23 (1984), p. 134.

[12] I. Suárez-Ruiz, L. Martínez, P. Bertrand, J.G. Prado and J.-D. Disnar, Int. J. Coal Geol. 25 (1994), p. 47.

[13] A. Jiménez, M.J. Iglesias and I. Suárez-Ruiz, J. Anal. Appl. Pyrolysis 46 (1998), p. 127.

[14] P.G. Hatcher, J.-L. Faulon, K.A. Wenzel and G.D. Cody, Energ. Fuels 6 (1992), p. 813.

[15] P.G. Hatcher, H.E. Lerch III and T.V. Verheyen, Int. J. Coal Geol. 13 (1989), p. 65.

[16] J.-Z. Dong and K. Ouchi, Fuel 68 (1989), p. 710.

[17] P.G. Hatcher, K.A. Wenzel, G.D. Cody, in: P.K. Mukhopadhyay, W.G. Dow (Eds.), Vitrinite Reflectance as a Maturity Parameter. Applications and Limitations. Proceedings of 
the ACS Symposium Ser., col 570, American Chemical Society, Washington, DC, 1994. p. 112.

[18] M.G. Flower, T. Gentzis, F. Goodarzi and A.E. Foscolos, Org. Geochem. 17 (1991), p. 805 .

[19] W.A. Hartgers, J.S. Sinninghe Damsté, J.W. de Leeuw, Y. Ling and G.R. Dyrkaczm, Energ. Fuels 8 (1994), p. 1055.

[20] R. Ceylan and J.B. Bredenberg, Fuel 61 (1982), p. 377.

[21] J.B. Bredenberg and R. Ceylan, Fuel 62 (1983), p. 342. 